\title{
CONTAINER FOR THE TRANSPORTATION AND CONSERVATION OF IMMUNOBIOLOGICALS
}

\author{
C. B. Soares ${ }^{\mathrm{a}}$, \\ M. N. E. Reis ${ }^{b}$, \\ B. Takane ${ }^{\text {c }}$, F. M. de Almeida ${ }^{c}$ \\ ${ }^{\mathrm{a} C e n t r o ~ F e d e r a l ~ d e ~ E d u c a c ̧ a ̃ o ~ T e c n o l o ́ g i c a ~ d e ~}$ \\ Minas Gerais - Av. Amazonas, 5253 - Nova \\ Suiça - Belo Horizonte - MG - Brasil - CEP \\ 30480-000 \\ cleide.barbosa@ig.com.br \\ ${ }^{b}$ Departamento de Engenharia Mecânica da \\ Pontifícia Universidade Católica de Minas \\ Gerais - Av. Dom José Gaspar, 500 - Coração \\ Eucarístico - Belo Horizonte - MG - Brasil - \\ CEP 30535-610. \\ mara@pucminas.br \\ ${ }^{\mathrm{c}}$ Estudante de Engenharia de Controle e \\ Automação da Pontifícia Universidade Católica \\ de Minas Gerais - Av. Av. Dom José Gaspar, \\ 500 - Coração Eucarístico - Belo Horizonte - \\ MG - Brasil - CEP 30535-610 \\ banjoutakane@hotmail.com \\ fmota01@gmail.com

\begin{abstract}
A container was developed for the transport and conservation of immunological products under low temperatures of between 2 and $8^{\circ} \mathrm{C}$, within a time span of 8 hours. The container is practical, simple and userfriendly, and can be used in places without electric power, and all these

The container proposed aims at meeeting the demand of the Programa Nacional de Imunizações (PNI- the National Immunization Program), through Cold Chain, which sets the standards for all the procedures concerning conservation, handling, distribution and transport of the vaccine from the laboratory that produces it to the moment of inoculation.

Innitially, the container was specifically developed for Vaccine for Inactive Influenza Virus against flu, which, according to a survey conducted with laboratories, is the most widely consumed, and whose conservation time span is also applicable to other immunobiologicals

After the design and construction of the prototype, the container was exhaustively tested under different weather conditions. The results of the experiment are being exposed and discussed in this paper and the prototype lived up to the expectations of the reserachers in terms of the time spans and temperatures foreseen for the conservation of the vaccine selected.
\end{abstract} \\ advantages are added of low operational costs. \\ Key words: Container, immunobiologicals, Cold Chain.
}

\section{NOMENCLATURE}

$\mathrm{T}$ Temperature of the vaccine at a certain moment $\left[{ }^{\circ} \mathrm{C}\right]$.

$\mathrm{T}_{\infty} \quad$ Room temperature $\left[{ }^{\circ} \mathrm{C}\right]$.

$\mathrm{T}_{\mathrm{V}} \quad$ Temperature of the vaccine at the beginning of the monitoring process $\left[{ }^{\circ} \mathrm{C}\right]$.

$\theta \quad$ Represents temperature.

$t$ Period of time of conservation of the vaccine at the interval of 2 a $8^{\circ} \mathrm{C}[\mathrm{h}]$.

$\mathrm{t} * \quad$ Desirable time of 8 hours.

$\delta \quad$ Represents time.

$\theta_{\text {máx }} \quad$ Non-dimensional of maximum temperature of vaccine.

$\theta$ min Non-dimensional of minimum temperature of vaccine.

\section{INTRODUCTION}

From the early days of humanity morbimortality rates (mortality caused by disease) has been very high, thus there emerged with the evolution of the biological sciences a pressing need for scientific research geared to the development of methods and parameters to reduce this rate.
This research effort led to the creation of vaccines and immunobiologicals, defined as microorganisms used to provoke active immunity states against certain infectious diseases. The vaccines are made of attenuated viruses, producing antibodies and antitoxins. In order to ensure that immunobiologicals preserve their initial characteristics, it is vital that they are refrigerated at temperatures of between 2 and $8^{\circ}$ $\mathrm{C}$, which can preserve their immunobiological capacity. The immunobiologicals are thermolabil and as such they will deteriorate after a certain time of exposure to temperatures inadequate to their preservation, since heat will speed the process of inactivation of the immunogenic components. The Cold Chain Manual, written by Funasa (2001), includes the norms and procedures for all the processes involved in the storage, conservation, handling, distribution and transportation of immunobiologicals of PNI (Programa Nacional de Imunizações - The National Immunization Program). The procedures described in this manual dictate that the immunobiologicals must be placed and transported in polystyrene or polythene boxes, previously encircled by recyclable ice spools, and that during vaccination campaigns ice cubes of 
scraped ice must be used inside plastic bags. This is a completely unacceptable practice, once the plastic bags with ice, due to their irregular shape, make it difficult for the immunobiologicals to be duly ensconced, and the empty spots inside these bags compromise thermal insulation, thus jeopardizing temperature maintenance. On top of all that, when the professional opens the box to handle the vaccine, he or she will be exposing all the other vaccines to the heat that comes from outside, and which will speed the heating process.

A number of studies have been carried out on the conservation of immunobiologicals. Sbeghen (1998), concluded that the system used for the conservation of the vaccines is vital if the quality of the vaccines is to be guaranteed; and the main cause for the loss of vaccines in the public vaccination programs in the US is the inadequacy of Cold Chain.

Rizzo et al. (1990) observed in an experiment that photosensibility and thermostability are determining factors in the fall of potency when the vaccines are exposed to the incidence of light. Exposure of the vaccines to heat leads to low stability and reduction of homogeneity.

Malinverni (2003), concluded that any breach in this Cold Chain may cause the vaccine to lose its immunization property, since there is a direct correlation between the effectiveness of the vaccines and the maintenance of the cold chain at every stage, that is, form their production to their storage, to transport and handling.

The mode of conservation of biological products, according to Hoffmeister (2001), must be as adequate as possible, because the temperatures outside the conservation band will affect the effectiveness of the vaccine and cause localized reactions in the patients.

After experimental tests, Albas et al. (2001) published that the anti-rabies vaccine produced in the brains of newly-born mice practically lost its capacity to induce neutralizing anti-bodies when frozen. Such conditions have rendered the vaccine useless for pigs and most probably for human beings.

The purpose of the project was to research into the reliability of the current procedures, seeking the likely optimization of the process and securing the maintenance of the quality of the vaccines as well as the enhancement of the process as a whole by implementing vaccination campaigns.

The container was developed, built and tested in order to assist the Cold Chain professionals, by guaranteeing the quality and the effectiveness of the immunobiologicals, rendering handling easier, promoting functionality, opperationality and low implantation costs.

\section{METODOLOGY}

Today, the Cold Chain is used in the transport and conservation of conventional vaccine boxes made of polystyrene or polyurethane, surrounded by recyclable ice spools and filled with the packaging containing the vaccines.

Taking as a basis the Cold Chain Manual, a polystyrene container was designed for the maintenance of the temperature inside it, at the band needed for the effective conservation of the vaccines, and keep the thermo condition of each vaccine unaltered while they are being transported and while the vaccines are being inoculated.

So that the inner space is better used, holding the largest possible number of units, the individual thermal insulation of each corner of the container was carefully studied as well as the improvement of the inner layout of the box.

The inner space of the container has two polystyrene grids for the vertical storage of the vaccines, making it possible for individual caps to be used, so that one vaccine can be handled without altering the temperature of the others. It also has four thermal ice walls that work as a barriers, preventing heat from the outside from entering the interior of the box.

\section{DESCRIPTION OF THE CONTAINER}

The container developed is of a rectangular shape, $610 \mathrm{~mm}$ long, $430 \mathrm{~mm}$ wide and $210 \mathrm{~mm}$ high, and has a capacity for 32 units. For the building of the prototype the material of choice was a P2 polystyrene plate, with a density of $220 \mathrm{~kg} / \mathrm{m}^{3}$ and $30 \mathrm{~mm}$ thick, according to Fig. 1 .

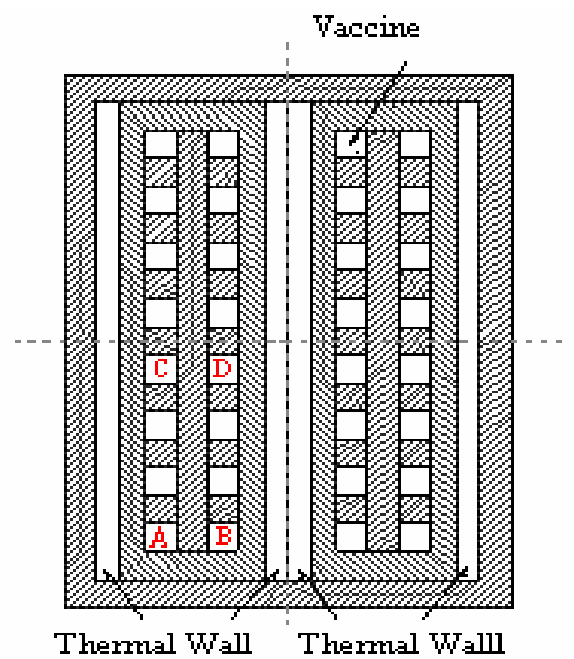

Figure 1. A, B, C and D position of the thermocouples during the tests. 


\section{DESCRIPTION OF THE THERMAL WALLS}

The dimensions of the thermal walls are similar to those of the recyclable ice spools used today in the vaccination practices, being $510 \mathrm{~mm}$ long, 120 $\mathrm{mm}$ high e $20 \mathrm{~mm}$ thick, as indicated in Fig. 1.

\section{EXPERIMENTAL PROCEDURE}

The experimental tests were conducted in three different environments, in conditions that are the most usual possible in terms of real current practices. They are as follows:

Test 1:non-refrigerated closed environment without incidence of sunlight.

Test 2: open air in the shade.

Test 3: open air with direct incidence of sunlight.

\section{POSITION OF THE THERMOCOUPLES}

Since the symmetry of the developed container is $x y$; its thermal behavior was analyzed by means of the study of one fourth of the system. This is the reason why the thermocouples were positioned as shown in Fig. 1.

\section{DATA COLLECTION}

The data on the temperature of the system were collected by means of a Tpaq 100 data collection plate, produced by Datapaq Inc, capable of storing 16,000 measurement values, through 8 data collection channels. This plate operates with thermopairs of the $\mathrm{K}$ type, have a resolution of $0.1^{\circ}$ $\mathrm{C}$ and precision of $\pm 1^{\circ} \mathrm{C}$.

Table 1 - Error in the measurement of the thermocouples by taking as a basis the standard thermocouples.

\begin{tabular}{|c|c|c|c|c|c|c|c|c|c|}
\hline \multicolumn{10}{|c|}{ THERMOCOUPLES } \\
\hline \multirow{3}{*}{$\begin{array}{l}\text { TIME } \\
\text { (min) }\end{array}$} & \multirow{3}{*}{ STANDARD } & \multicolumn{8}{|c|}{ TEMPERATURES ${ }^{\circ} \mathrm{C}$} \\
\hline & & \multicolumn{2}{|c|}{ POSITION A } & \multicolumn{2}{|c|}{ POSITON B } & \multicolumn{2}{|c|}{ POSITION C } & \multicolumn{2}{|c|}{ POSITION D } \\
\hline & & I & IM & $\mathrm{I}$ & IM & I & IM & $\mathrm{I}$ & IM \\
\hline 5 & 0.90 & 0.30 & -0.60 & 0.60 & -0.30 & 0.50 & -0.40 & 0.40 & -0.50 \\
\hline 10 & 1.70 & 1.20 & -0.50 & 1.40 & -0.30 & 1.20 & -0.50 & 1.40 & -0.30 \\
\hline 15 & 2.20 & 2.00 & -0.20 & 2.20 & 0.00 & 2.10 & -0.10 & 2.10 & -0.10 \\
\hline 20 & 2.90 & 2.90 & 0.00 & 3.00 & 0.10 & 2.90 & 0.00 & 2.90 & 0.00 \\
\hline 25 & 3.60 & 3.70 & 0.10 & 3.90 & 0.30 & 3.80 & 0.20 & 3.90 & 0.30 \\
\hline 30 & 4.50 & 4.90 & 0.40 & 5.00 & 0.50 & 5.00 & 0.50 & 5.00 & 0.50 \\
\hline 35 & 5.30 & 5.70 & 0.40 & 5.80 & 0.50 & 5.70 & 0.40 & 5.80 & 0.50 \\
\hline 40 & 6.40 & 6.60 & 0.20 & 6.80 & 0.40 & 6.60 & 0.20 & 6.70 & 0.30 \\
\hline 45 & 7.20 & 7.50 & 0.30 & 7.60 & 0.40 & 7.60 & 0.40 & 7.60 & 0.40 \\
\hline 50 & 8.10 & 8.00 & -0.10 & 8.00 & -0.10 & 7.90 & -0.20 & 8.00 & -0.10 \\
\hline 55 & 9.00 & 8.80 & -0.20 & 8.90 & -0.10 & 8.90 & -0.10 & 8.90 & -0.10 \\
\hline 60 & 9.80 & 9.40 & -0.40 & 9.40 & -0.40 & 9.40 & -0.40 & 9.40 & -0.40 \\
\hline 65 & 10.40 & 10.20 & -0.20 & 10.30 & -0.10 & 10.20 & -0.20 & 10.30 & -0.10 \\
\hline 70 & 11.50 & 10.80 & -0.70 & 10.90 & -0.60 & 10.80 & -0.70 & 10.90 & -0.60 \\
\hline & & \multicolumn{2}{|c|}{$\mathrm{E}_{\max }=0.70$} & \multicolumn{2}{|c|}{$\mathrm{E}_{\max }=0.60$} & \multicolumn{2}{|c|}{$\mathrm{E}_{\max }=0.70$} & \multicolumn{2}{|c|}{$\mathrm{E}_{\max }=0.60$} \\
\hline & & \multicolumn{2}{|c|}{$\mathrm{E}_{\min }=0.00$} & \multicolumn{2}{|c|}{$\mathrm{E}_{\min }=0.00$} & \multicolumn{2}{|c|}{$\mathrm{E}_{\min }=0.00$} & \multicolumn{2}{|c|}{$E_{\min }=0.00$} \\
\hline & & \multicolumn{2}{|c|}{$\mathrm{E}_{\text {mean }}=0.30$} & \multicolumn{2}{|c|}{$\mathrm{E}_{\text {mean }}=0.30$} & \multicolumn{2}{|c|}{$\mathrm{E}_{\text {mean }}=0.30$} & \multicolumn{2}{|c|}{$\mathrm{E}_{\text {mean }}=0.30$} \\
\hline
\end{tabular}

IT BEING: I = Uncertainty $\quad \mathrm{IM}=$ Mean uncertainty

\section{METHODOLOGY FOR THE CALIBRATION OF THE THERMOCOUPLES AND ERROR}

Once a contact digital thermocouple had been defined as standard, a mixture of ice and water was prepared, and 15 (fifteen) temperature measurement were taken with 04 (four) thermocouples used in the experiment and connected to the DATAPAQ data collection plate.

Table 1 shows the error in the measurements of each thermocouple, by taking as a basis the behaviour of the thermocouple defined as being standard. The variations are not very significant, once the temperature for the conservation of the vaccine may fluctuate between 2 and $8^{\circ} \mathrm{C}$.

\section{RESULTS OBTAINED}

In the presentation of the results the temperature and time variables were nondimentionalised, having behaved in this way, as a whole, during the monitoring process in the Tests 1 , 2 and 3 proposed:

$\theta=\left(\mathrm{T}-\mathrm{T}_{\infty}\right) /\left(\mathrm{T}_{\mathrm{V}}-\mathrm{T}_{\infty}\right)$ represents temperature; $\mathrm{T}_{\infty}$ room temperature; $\mathrm{T}$ the temperature of the vaccine at a certain moment and $\mathrm{T}_{\mathrm{V}}$ the temperature of the vaccine at the beginning of the monitoring process.

$\delta=\mathrm{t} / \mathrm{t} *$ represents time; $\mathrm{t}$ represents the period of time of conservation of the vaccine at the interval of 2 to $8^{\circ} \mathrm{C}$, and $\mathrm{t} *$ the desirable time of 8 hours. This non-dimensional represents the 
parameters that indicate the performance of the system.

The diagrams show the mean temperatures obtained from the vaccines during the monitoring process. This parameter satisfactorily represents the thermal behavior of the vaccine, the standard deviation being negligible and the means, modes e medians having practically the same values.

\section{RESULTS OF THE EXPERIMENTAL TESTS - TEST 1}

The mean temperature profile obtained is inside the tolerance band indicated by $\theta$ maximum and $\theta$ minimum. As a result, the vaccine was conserved for a much longer period of time than the expected.

The conservation time of the vaccine during the experiments, at the interval of 2 to $8^{\circ} \mathrm{C}$, was of approximately 17 hours, that is, 2.125 longer than the desirable period of time.

Table 2 shows the mean values of $\theta$ obtained in the positions $\mathrm{A}, \mathrm{B}, \mathrm{C}$ and $\mathrm{D}$.

Table 2 - The mean values of $\theta$ obtained in the positions A, B, C and D.

\begin{tabular}{|c|c|c|c|c|}
\hline \multicolumn{3}{|c|}{ TEST } & \multicolumn{2}{|c|}{$-\theta$ Values } \\
\hline$\delta=\mathrm{t} / \mathrm{t} *$ & Mean & Median & Mode & $\begin{array}{c}\text { Standard } \\
\text { Deviation }\end{array}$ \\
\hline 0,00 & 1,00 & 1,00 & 1,00 & 0,00 \\
\hline 0,25 & 1,10 & 1,10 & 1,11 & 0,01 \\
\hline 0,50 & 1,10 & 1,10 & 1,11 & 0,01 \\
\hline 0,75 & 1,10 & 1,10 & 1,10 & 0,00 \\
\hline 1,00 & 1,11 & 1,11 & 1,11 & 0,00 \\
\hline 1,25 & 1,11 & 1,10 & 1,10 & 0,01 \\
\hline 1,50 & 1,11 & 1,11 & 1,11 & 0,00 \\
\hline 1,75 & 1,11 & 1,11 & 1,10 & 0,01 \\
\hline 2,00 & 1,11 & 1,10 & 1,11 & 0,01 \\
\hline 2,25 & 1,10 & 1,10 & 1,10 & 0,00 \\
\hline
\end{tabular}

In Test 1, the temperature curve remained unchanged for the values of $\theta$ above 1.00, leading to the conclusion that the temperatures of the vaccines stabilized at very low values, below the temperature at the beginning of the process, according to Fig. 2.

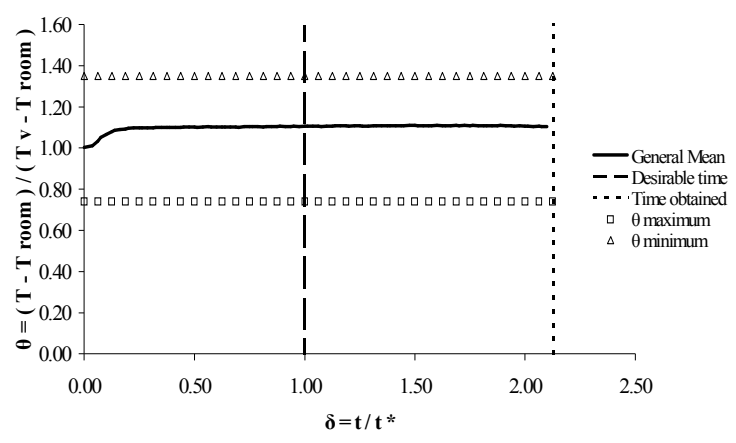

Figure 2. Profile of the mean temperature in the positions A, B, C and D - Test 1 .

Figure 3 shows the period of time the temperature of the vaccine was maintained as a result of the position of each thermopair. In position A, due to the vaccine's closeness to the outer wall, its conservation time was shorter when compared to the other positions, which indicates the evaluation of the behavior of the container in terms of the conservation time obtained in position A.

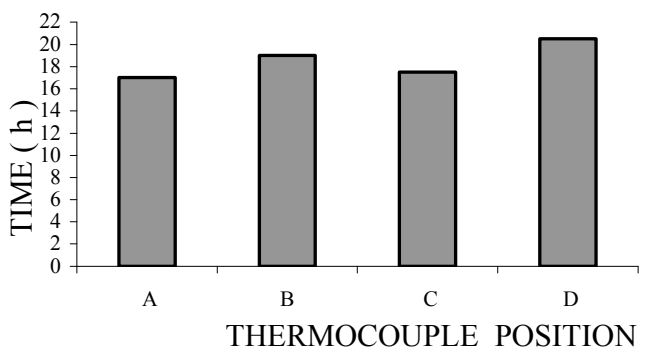

Figure 3. Temperature maintenance time of the vaccine $\mathrm{x}$ Position of each thermopolar inside the container.

\section{RESULTS OF THE EXPERIMENTAL TESTS - TEST 2}

The majority of the vaccination practices occur in the open air in the shade, and the proposed container lived up to the expected performance; with a slight rise in the temperature of the immunibiologicals at the beginning of the process and after the stabilization for the values of $\theta$ close to 1.00 . It was concluded that the temperatures of the vaccines remained practically the same as those at the beginning of the process.

The conservation time of the vaccine at the interval 2 to $8^{\circ} \mathrm{C}$, obtained during the experiments in this test was of 17.5 hours, that is, 2.1875 times longer than the expected time.

Table 3 shows the mean values of $\theta$ obtained in the positions $\mathrm{A}, \mathrm{B}, \mathrm{C}$ and $\mathrm{D}$.

Table 3 - The mean values of $\theta$ obtained in the positions A, B, C and D.

\begin{tabular}{|c|c|c|c|c|}
\hline \multicolumn{4}{|c|}{ TEST $2-\theta$ Values } \\
\hline$\delta=\mathrm{t} / \mathrm{t} *$ & Mean & Median & Mode & $\begin{array}{c}\text { Standard } \\
\text { Deviation }\end{array}$ \\
\hline 0,00 & 1,00 & 1,00 & 1,00 & 0,00 \\
\hline 0,25 & 1,00 & 1,01 & 0,96 & 0,03 \\
\hline 0,50 & 0,99 & 1,01 & 0,95 & 0,03 \\
\hline 0,75 & 0,99 & 1,02 & 0,96 & 0,03 \\
\hline 1,00 & 1,00 & 1,03 & 0,97 & 0,03 \\
\hline 1,25 & 1,02 & 1,04 & 0,99 & 0,03 \\
\hline 1,50 & 1,03 & 1,06 & 1,00 & 0,03 \\
\hline 1,75 & 1,04 & 1,06 & 1,00 & 0,03 \\
\hline 2,00 & 1,03 & 1,06 & 1,00 & 0,03 \\
\hline 2,25 & 1,02 & 1,03 & 1,01 & 0,02 \\
\hline
\end{tabular}


Fig.4 indicates a very coherent temperature profile, the thermal behavior being that foreseen for the system, taking into consideration the environment proposed, which contributed to cause a slight rise in the temperature of the system as a whole at the beginning of the monitoring process.

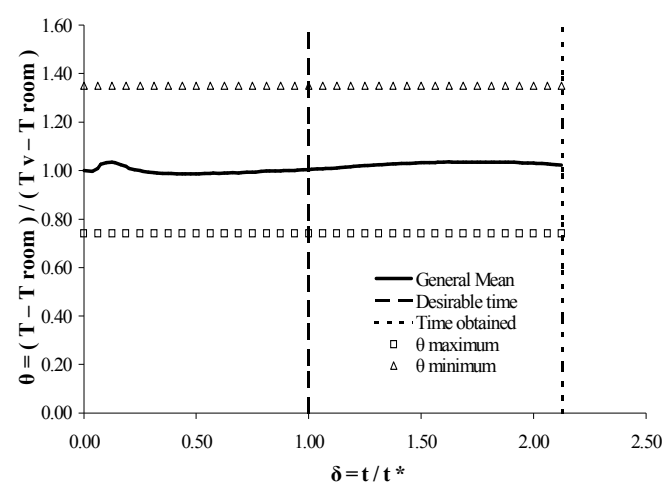

Figure 4. Profile of the mean temperature in the positions A, B, C and D-Test 2.

The thermopair in position $A$, due to its proximity to the environment outside, presented the shortest conservation periods of time of the vaccine within the temperature band recommended, thus defining the performance of the container in the environment proposed in Test 2.

Figure 5 shows the temperature maintenance time as a result of the position of each thermopair in the container.

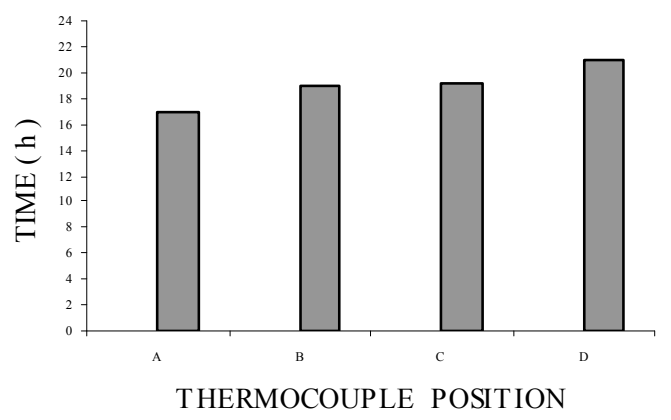

Figure 5. Temperature maintenance time of the vaccine $x$ position of each thermopair in the container

\section{RESULTS OF THE EXPERIMENTAL TESTS - TEST 3}

The mean temperature profile obtained remained for a long time below what was expected, within the band of tolerance indicated by $\theta$ maximum and $\theta$ minimum.
The vaccine's conservation time obtained during the experiments, at the interval 2 to $8^{\circ} \mathrm{C}$, was of approximately 2 hours, that is, 0.250 of the desired time.

In the environment proposed, Test 3, the vaccine's conservation times were too short in relation to the desired time, due to the direct incidence of sunlight, which caused the immunobiologicals to heat slightly; as indicated in Figures 6 and 7, respectively.

Table 6 shows the mean values of $\theta$ obtained in positions $\mathrm{A}, \mathrm{B}, \mathrm{C}$ and $\mathrm{D}$.

\begin{tabular}{|c|c|c|c|c|}
\hline \multicolumn{5}{|c|}{ TEST 3 $-\theta$ Values } \\
\hline$\delta=\mathrm{t} / \mathrm{t} *$ & Mean & Median & Mode & $\begin{array}{c}\text { Standard } \\
\text { Deviation }\end{array}$ \\
\hline 0,00 & 1,00 & 1,01 & 1,00 & 0,01 \\
\hline 0,06 & 0,97 & 0,98 & 0,98 & 0,01 \\
\hline 0,13 & 0,95 & 0,97 & 0,97 & 0,01 \\
\hline 0,19 & 0,93 & 0,95 & 0,91 & 0,02 \\
\hline 0,25 & 0,93 & 0,96 & 0,92 & 0,02 \\
\hline
\end{tabular}

Table 6 - $\theta$ mean values in positions A, B, C and D - Test 3

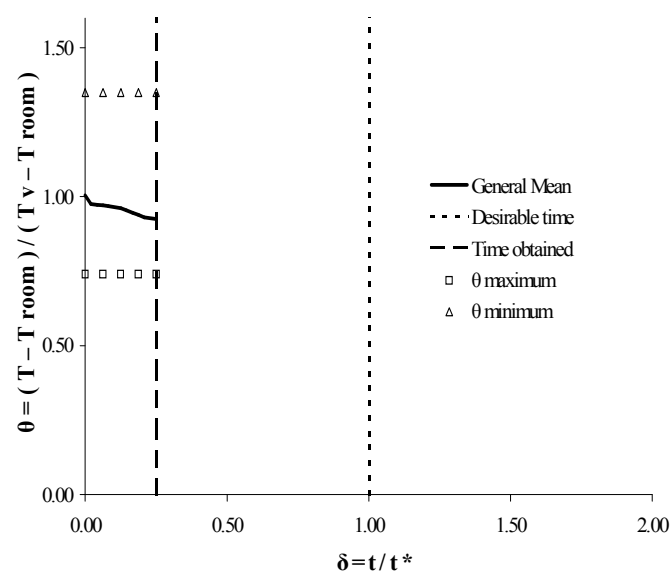

Figure 6. Mean temperature profile in positions $A$, $\mathrm{B}, \mathrm{C}$ and $\mathrm{D}-$ Test 3

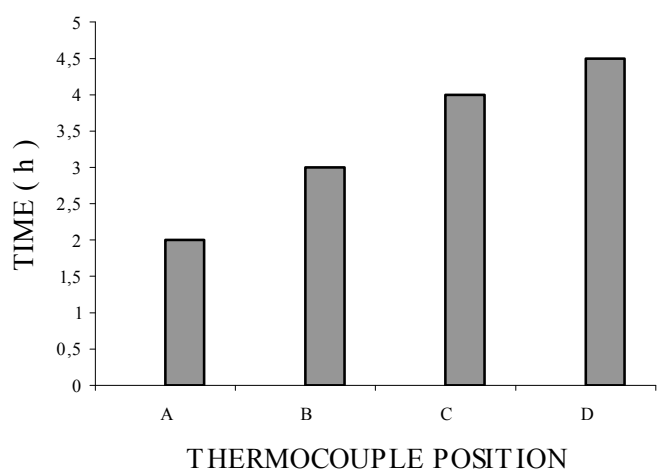

Figure 7. Time of maintenance of the temperature of the vaccine $\mathrm{x}$ Position of each thermopair inside the container. 


\section{COMPARATIVE ANALYSES BETWEEN TESTS 1 AND 2}

In this section we compared the mean temperature and time obtained from the monitoring of the vaccines in Tests 1 and 2, for which the performance of the container was satisfactory. The purpose of this analysis was to establish a practical and dependable parameter of the mean time for the use of the container, adequate to the temperature band of conservation of the vaccine and desirable time for the maintenance of the dependability of the quality of the immunobiologicals.

The Fig. 8 indicates the mean temperature profile obtained in Tests 1 and 2 with minimum conservation times of 17 and 17.5 hours, respectively, which is 9 and 9.5 hours in excess of the expected time.

Table $8-\theta$ mean values in the positions $\mathrm{A}, \mathrm{B}, \mathrm{C}$ and D - Tests 1 and 2 .

\begin{tabular}{|r|r|r|r|c|}
\hline \multicolumn{5}{|c|}{ TESTS 1 and $2-\theta$ Values } \\
\hline$\delta=\mathrm{t} / \mathrm{t} *$ & Test 1 & Test 2 & Mean & $\begin{array}{c}\text { Standard } \\
\text { Deviation }\end{array}$ \\
\hline 0,00 & 1,00 & 1,00 & 1,00 & 0,00 \\
\hline 0,25 & 1,14 & 1,00 & 1,07 & 0,10 \\
\hline 0,50 & 1,14 & 0,99 & 1,07 & 0,11 \\
\hline 0,75 & 1,14 & 0,99 & 1,07 & 0,11 \\
\hline 1,00 & 1,14 & 1,00 & 1,07 & 0,10 \\
\hline 1,25 & 1,15 & 1,02 & 1,09 & 0,09 \\
\hline 1,50 & 1,15 & 1,03 & 1,09 & 0,08 \\
\hline 1,75 & 1,15 & 1,04 & 1,10 & 0,08 \\
\hline 2,00 & 1,15 & 1,03 & 1,09 & 0,08 \\
\hline 2,13 & 1,14 & 1,02 & 1,08 & 0,08 \\
\hline
\end{tabular}

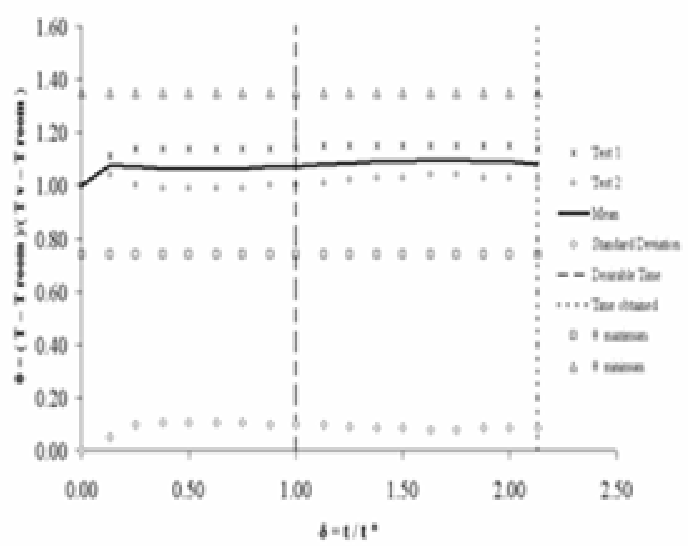

Figure 8. Mean temperature Profile Tests 1 and 2.

Concluding that the proposed container had a very good response in the environments represented by Tests 1 and 2, they can be used with a very high rate of dependability and performance in either environment.

\section{CONCLUSIONS}

The purpose of this study was to develop a container to be used in the transportation and conservation of immunobiologicals, for a minimum 8 hours in a temperature between 2 and $8^{\circ} \mathrm{C}$.

The differential between the designed container and the existing ones lays the position the vaccines are enclosure in niches, which allows easy handling and provides individual thermal insulation.

After the container was developed, tests were run considering the three environments proposed: Test 1 (in a closed room without refrigeration or incidence of sunlight); Test 2 (in the open air, in the shade) and Test 3 (in the open air with incidence of sunlight).

The results obtained led to the conclusion that in environments without direct incidence of sunlight, besides living up the expectations, the container outdid the performance foreseen concerning desirable conservation time of the immunobiologicals within the temperature band desired. However, in places where the container was exposed to the sunlight, the conservation times were not satisfactory.

In Test 1 , the immunobiological remained at a temperature stabilized above the temperature at the beginning of the process, but within the temperature band desired for 17 hours.

As for the second environment proposed, (Test 2 ), the monitoring process showed that despite the stabilization of the temperatures a little above the rate of stabilization observed in Test 1 , the mean time of maintenance of the immunobiologicals within the temperature band required was of 17.5 hours.

In Test 3, as the time obtained was of 2 hours in this environment, heat penetrated mainly through the upper side of the container, which was continuously exposed to direct sunlight, since this side had no thermal walls (barriers).

The conservation time of the container that guarantees the dependability of the immunibiologicals is of 17 hours.

After the conclusion of the project and collection of the experimental results, a patent report was written and submitted to INPI under the provisional registration number 014060000622 .

As suggestions for further studies we indicate: Project and study a more effective thermal insulation technique with the inclusion of barriers (walls) in the upper surface of the container, besides a study of a mathematical model capable of simulating adverse temperature and dimension conditions.

\section{ACKNOWLEDGEMENTS}

To Federal University of Minas Gerais UFMG, through FUNDEP (Foundation of Research and Development of UFMG). 


\section{REFERENCES}

Albas, A., Nogueira, R. M. B., Fontolan, O. L., Albas, K. S. and Neto, H. B., 2001, The effect of freezing on immunogenicity of the rabies vaccine produced in suckling mouse brain, Revista da Sociedade Brasileira de Medicina Tropical, São Paulo, Brazil.

Côrtes, G. and Papaiordanou, P., 2002, $<$ http:www.riscobiológico.org.>, Acesso em 7 fev. 2005, Armazenamento de Imunobiológicos e Rede de Frio, São Paulo, Brazil.

Datapaq Ltd., Tracker System - 1977, Manual de Operação. Datapaq Ltd., Cambrige.

Funasa, 2001; Manual de Rede de Frio, Ministério da Saúde, Brasília, Brazil.

Hoffmeister, T. 2001, $<$ http:www.fortdodge.com.br>, Acesso em 14 fev. 2005, Conservação de Vacinas, São Paulo, Brazil.

Incropera, F. P. and Dewitt, D. P., 1990, Fundamentos de Transferência de Calor e Massa, Guanabara Koogan, John Wiley \& Sons, New York, EUA.

Malinverni, C., 2003, Distribuição de Imunobiológicos, Fomento de Educação Sanitária e Imunização em Massa contra Doenças Transmissíveis, São Paulo, Brazil.

Rizzo, E., 1990, Photosensitivity and stability of freeze-dried and reconstituted (Biken CAM-70) strain measles vaccines, Revista de Saúde Pública, Vol. 24. São Paulo, Brazil.

Sbeghen, C. C., 1998, $<$ http:www.medstudents.com.br/content/resumos $>$, Acesso em 20 fev. 2005, Imunizações, Conservação, Transporte e Manuseio de Vacinas, Termoestabilidade das Vacinas. 